\title{
Evaluation of maintenance performance in a Metalworking Company: a case study and proposal of new indicators
}

\author{
Teonas Bartz, Julio Cezar Mairesse Siluk \\ Federal University of Santa Maria \\ e-mail: efficacy.consultoria@gmail.com; jiluk@ufsm.br
}

\begin{abstract}
In Brazil, companies work primarily with preventive and predictive maintenance (BRAZILIAN..., 2009). The maintenance sector has been strategic for companies to achieve results efficiently and with planned costs. However, the maintenance indicators are not usually analyzed. The purpose of this study was to analyze the maintenance performance of a metallurgical company and to identify potential maintenance indicators that may be adopted by that enterprise. Thus, it is expected that the maintenance sector be more competitive and efficient, contributing to the achievement of results. In order to do so, data and time periods of maintenance, nature of maintenance, and service plan for preventive maintenance were collected from the company's control system for the time period of one year. After that, the data were catalogued onto a spreadsheet. Then, the suggested indicators that were relevant to the availability of equipment for production as well as to the percentage of hours worked in preventive/predictive maintenance compared to corrective maintenance were analyzed. Preliminary results showed that the programming methodology adopted for maintenance in this study improved the availability of equipment for production and also the time of corrective maintenance, which it is of great importance.
\end{abstract}

Keywords: maintenance planning, performance evaluation, performance indicators, strategic management, competitiveness.

\section{Introduction}

The maintenance sector undergoes a change of concept by entrepreneurs. Until recently regarded as an industry to support the production, currently is seen as a strategic sector, as to meet the expected results, the machinery and equipment must meet the expectations and plans made. Maintenance, with a strategic vision for a competitive environment, is to seek recovery of damages beyond the quality and productivity; interfering with organizational outcomes (OTANI; MACHADO, 2008). These components are related to a modern management system and an efficient, economical and profitable (KHAN; DARRAB, 2010). But even so, the maintenance performance is not evaluated in most organizations and the limited use of performance indicators makes clear the deficiency. To solve this problem, maintenance management is essential given the results by maximizing the availability, reduction in the number of failures of equipment, increasing the time between repairs on the same equipment, improved safety and increased equipment reliability.

The performance of the maintenance of production equipment is of paramount importance for companies to achieve the highest possible return on their investment. For both techniques are used and maintenance strategies focused on prevention of equipment failure; increasing availability and reliability for operation thereof when in use. Among these strategies and techniques to emphasize preventive maintenance, predictive maintenance total productive and more recently, the reliability-centered maintenance. For Khalil, Saad and Gingy (2009) is interesting for all companies to develop a preventive maintenance strategy, especially to eliminate unplanned downtime of equipments.

This paper proposes to study the conditions of maintenance management of a firm metallurgical located in southern Brazil. The focus of the study is to identify the efficiency of maintenance, through analysis of existing maintenance indicators, propose a working methodology and evaluate the system after implementation of the proposed methodology. To this end, the data collected were the times and periods of maintenance, the nature of maintenance and care plan preventive maintenance. All these data were collected from EMS ERP Datasul ${ }^{\odot}$. Data collection took one year and collected data were tabulated with the aid of Microsoft Excel $^{\odot}$ spreadsheet. After analysis, suggested new indicators relevant to better assess the performance of maintenance. 
Preliminary results show that the programming methodology adopted for maintenance from this study, increased the availability of equipment for production and also the time between corrective maintenance, which is of great importance when it comes to maintenance. For review of maintenance indicators, measuring the effectiveness of actions taken can be better evaluated in the medium and long term.

\section{Performance of procedures}

Moayed and Shell (2009) show the relationship between all segments of a manufacturing process, identifying the limits of performance. Divide this level into three: production support, and business environment. The maintenance sector is classified as production support. Silva, Cabrita and Matias (2008) emphasize the importance of maintaining good results in efficiency in manufacturing. For these authors, the inherent motivation to practice new techniques and models for maintenance management is the use of Key Performance Indicators - KPIs for the maintenance sector.

Observing the performance indicators for maintenance, proposed by Muchiri et al. (2009), the measurement of plant performance, using indicators of productivity, based on the competitive strategies of firms could contain some more criteria to be evaluated as: lost profit for production losses and decreases the speed of the machines, overtime costs provided by breakdown of machinery and increased cost of energy to recover lost production.

\subsection{Performance measurement systems}

With the increasing integration of activities in manufacturing companies, organizations need to manage the processes widely, based on indicators and targets. For both, there are several ways to evaluate the performance of an organization. For Müller (apud SELLITTO; WALTER, 2006), systems of performance measurement best known are divided into four classes: models with financial emphasis; classical models, such as those proposed by the Total Quality Management - TQM, structured models, such as models proposed by the Balanced Scorecard - BSC, and specific models.

Industrial activities are increasingly paid, so traditional methods of measurement should be adopted in parallel with methods that assess the full utilization of productive capacity and cost the company. For Moraes and Mariano (2010), among the systems performance assessment adopted by companies, one that has gotten attention is the Balanced Scorecard - BSC, which should be treated not only as a measuring system, but also as a model learning and improvement.

Thus, one can say that there are several methods of measuring manufacturing performance. To Anvari, Edwards and Starr (2010), one of the most effective methods to perform this measurement is the Overall Equipment Effectiveness - OEE, a method that meets the needs of total productive maintenance and lean manufacturing. In respect of performance measurement of maintenance, Reis, Costa and Almeida (2009) point out several aspects that can be considered, such as preventive and predictive maintenance, maintenance strategies, maintenance and performance.

\subsection{The maintenance management}

According Ahrén and Parida (2009), measuring the performance of maintenance is a strategic factor for companies. Only the desired improvements are achieved from the control process. As in all areas of business, performance measurement aims at continuous improvement. In maintaining this goal cannot be different. Ahrén and Parida (2009) point out that the maintenance indicators are important to determine where the weaknesses of maintenance. Also note that these indicators are internal to the organization and should be well defined, standardized and disseminated to everyone involved with interpreting the same objectivity.

The maintenance performance indicators are used when one wants to evaluate the influence of the maintenance on manufacturing performance. In the evaluation of manufacturing performance are related to productivity, availability, quality and capacity utilization. The identification of which will be the maintenance indicators to adopt will be based on the organization >s strategy, aligning the goals and targets contained in its planning (PARIDA, 2007).

For Parida and Kumar (2006), measuring the performance of maintenance has some basic goals, such as measuring the value created for the maintenance, justify the company>s investment in maintenance, planning, investment in improvements, carry out the improvements related to health, safety and the work-environment. In addition to these basic objectives is to measure the performance of maintenance that will be raised the need to change the design or maintenance strategy used by organizations.

As a model for maintenance management, we can present the model proposed by Márquez et al. (2009) and shown in Figure 1. It is a model composed of eight sequential blocks. The first three blocks assess the effectiveness of maintenance, the fourth and fifth ensure the efficiency of maintenance, while the sixth and seventh blocks deal with the life cycle of equipment and the eighth block seeks continuous improvement.

It is observed in this model, as in any planning being done, the first phase is to determine the goals of the deployment model. From the goals, it begins to change in the most important because they represent a significant result when the problems are solved. No recurrence of stops and breaks you can plan preventive maintenance schedules and 
Phase 1

Definition of objectives and

indicators of maintenance

Phase 8

Continuous improvement and new techniques utilization

Phase 7

Analysis and improvement of the life cycle
Phase 2

Definition of maintenance strategyand asset

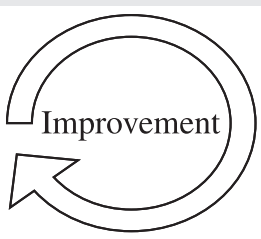

Phase 6

Execution, control and evaluation of maintenance
Phase 3

Immediate intervention in the weaknesses of high importance

Phase 4

Planning of preventive maintenance

Figure 1. Model of maintenance management (MÁRQUEZ et al., 2009).

elaborate parades. After the implementation of this schedule, we enter the phase of control and refinement of the model.

\subsection{Maintenance indicators}

As one of the most effective methods of measuring is OEE, some indicators pointed out by maintenance Muchiri et al. (2009), aligned with the OEE metric are shown in Figure 2.

The indicators of maintenance can be divided into two types: process indicators and leading indicators for maintenance of the result of handling (MUCHIRI et al., 2009). For these authors, the first type - the main indicators of maintenance evaluates whether the tasks are being performed adequately and, if later results are obtained. To check whether these objectives are evaluated to identify the work, planning of maintenance activities, the planning and execution of tasks. The second type - the outcome indicators - deals primarily with the availability of equipment for production, reliability and operating conditions thereof. OEE is important because it monitors the actual performance of a machine in relation to its performance in ideal conditions of production, revealing hidden losses of equipment. This concept is increasingly being introduced in industry, as it consolidates itself as the main measure of performance of companies that adopt the model of maintenance management based on total productive maintenance (ANVAR; EDWARDS; STARR, 2010).

\section{Status of maintenance in Brazil}

Every two years, the Brazilian Association of Maintenance - ABRAMAN disseminates research data conducted for companies in all sectors. In this research are evaluated and number of people involved in the maintenance of schooling, indicators mostly used, the hiring of outsourced services and other important data to assess the level of maintenance management in Brazil. The latest edition of the research was published in 2009, where the data presented below were removed.

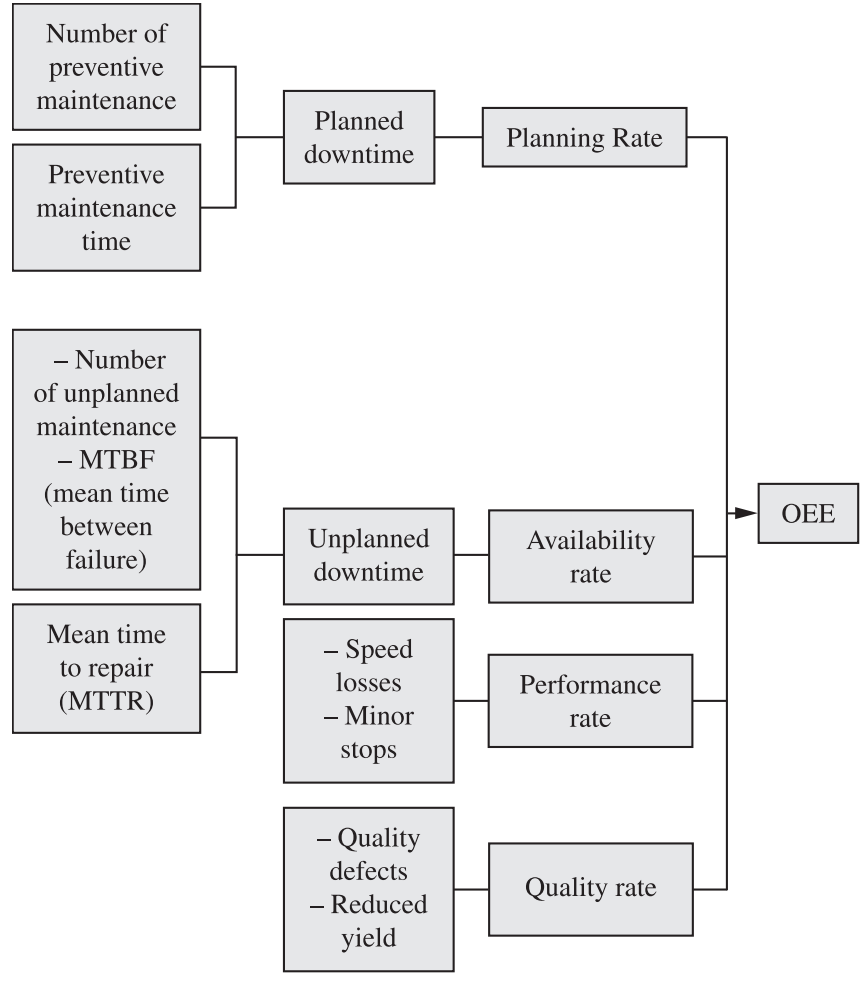

Figure 2. Performance indicators for maintenance in the OEE metric (MUCHIRI et al., 2009).

\subsection{Number of employees in the maintenance sector}

Table 1 shows the percentage of direct employees in the maintenance sector of the companies surveyed.

In 2009 this percentage reached $26.31 \%$ of total employees of companies allocated in the maintenance sector. This increase in percentage can be explained by the greater need to improve the occupation of production facilities and the growing market demand in response to periods by customers. Besides the lack of professionals in the market brought a greater appreciation of the professionals in this sector, which increased turnover, in search of better pay 
and opportunities for growth. This rotation is presented in Table 2.

\subsection{Investments in maintenance}

Regarding maintenance costs, companies have maintained a regular rate over the years surveyed, while in 2009 there was a greater investment in relation to gross revenues of the companies, with a rate of $4.14 \%$. These data are shown in Table 3.

The increase in investment in maintenance can be assessed by the fact that firms have increased their productive occupation at the end of 2009, but also because the first half of the year has presented a production below

Table 1. Number of employees in the maintenance sector (BRAZILIAN..., 2009).

\begin{tabular}{|c|c|c|c|}
\hline \multirow{2}{*}{ Year } & \multicolumn{3}{|c|}{ Number of employees in enterprises } \\
\cline { 2 - 4 } & Total - T & Maintenance - M & M / T \\
\hline 2009 & 111591 & 29355 & $26.31 \%$ \\
\hline 2007 & 163146 & 37921 & $23.24 \%$ \\
\hline 2005 & 108784 & 23651 & $21.74 \%$ \\
\hline 2003 & 109794 & 31504 & $28.69 \%$ \\
\hline 2001 & 159454 & 33015 & $20.71 \%$ \\
\hline 1999 & 133650 & 26257 & $19.65 \%$ \\
\hline 1997 & 154250 & 30750 & $19.94 \%$ \\
\hline 1995 & 320650 & 67375 & $21.01 \%$ \\
\hline
\end{tabular}

Table 2. Turnover of maintenance personnel (BRAZILIAN..., 2009).

\begin{tabular}{|c|c|}
\hline \multicolumn{2}{|c|}{ Annual turnover in the maintenance } \\
\hline Year & Mean $(\boldsymbol{\%})$ \\
\hline 2009 & 3.70 \\
\hline 2007 & 2.39 \\
\hline 2005 & 1.98 \\
\hline 2003 & 2.32 \\
\hline 2001 & 2.46 \\
\hline 1999 & 2.45 \\
\hline 1997 & 2.22 \\
\hline 1995 & 2.75 \\
\hline
\end{tabular}

Table 3. Cost of maintenance in relation to gross sales (BRAZILIAN..., 2009).

\begin{tabular}{|c|c|}
\hline Year & $\begin{array}{c}\text { Cost of maintenance / Gross } \\
\text { Revenue (\%) }\end{array}$ \\
\hline 2009 & 4.14 \\
\hline 2007 & 3.89 \\
\hline 2005 & 4.10 \\
\hline 2003 & 4.27 \\
\hline 2001 & 4.47 \\
\hline 1999 & 3.56 \\
\hline 1997 & 4.39 \\
\hline 1995 & 4.26 \\
\hline
\end{tabular}

capacity, the influence of the financial crisis started at the end of the year 2008. Thus, the relationship between spending and revenue increases in maintenance, because it leverages the low production period to perform the necessary maintenance and improvements to the process. These percentages are average values, since certain activities of the industry require greater investment in maintenance to revenue, such as transport companies.

Also, regarding the composition of the costs of maintenance, there is a regularity of expenditure. The main costs of the sector are spending on personnel, materials necessary for carrying out maintenance work and outsourcing services. These data are presented in Table 4, which divides the percentage of industry costs between each of these costs.

Observe that the indicator of spending on materials is the one that showed most significant change, increasing from $30.52 \%$ in 2007 to $33.43 \%$ in 2009 . Other indicators are stable, showing a trend in reduction of personnel expenses, which presents indicators decrease from the year 1997. An indicator that shows a growing trend is the hiring of subcontractors. The Table 5 which shows the trend of hiring these services by businesses.

One possible reading of this is the difficulty in hiring skilled labor for certain maintenance activities. Thus, organizations seeking to engage the services needed in companies.

\subsection{Types of maintenance adopted}

Regarding the method used for maintenance, it still can be seen that the preventive and corrective maintenance occupy most of the companies. The application of resources in maintenance, hours of maintenance services in relation to total working time is shown in Table 6.

A worrying statistic is the increase in the percentage of corrective maintenance and reduces the share of preventive and predictive maintenance. This type of maintenance is more expensive for businesses and may be related also to the fact that there are higher maintenance costs to revenue, shown in Table 3.

\subsection{Indicators used for maintenance}

The main indicators adopted are shown in Table 7. Among the internationally recognized indicators, the most mentioned are availability, Mean Time Between Failures - MTBF, Mean Time To Repair - MTTR and costs. Other indicators are also measured, such as rework, customer satisfaction, backlog - which according to Branco Filho (2006) is the time required performing all maintenance pending, if there is greater demand for maintenance.

Among the key performance indicators adopted by the companies surveyed, one can see that currently the most important is the operational availability, which in 2009 
Table 4. Composition of maintenance costs (BRAZILIAN..., 2009).

\begin{tabular}{|c|c|c|c|c|}
\hline \multirow{2}{*}{ Year } & \multicolumn{4}{|c|}{ Breakdown of costs (\%) } \\
\cline { 2 - 5 } & Personnel & Material & Outsourcing & Other \\
\hline 2009 & 31.09 & 33.43 & 27.27 & 8.21 \\
\hline 2007 & 32.35 & 30.52 & 27.20 & 9.93 \\
\hline 2005 & 32.53 & 33.13 & 24.84 & 9.50 \\
\hline 2003 & 33.97 & 31.86 & 25.31 & 9.86 \\
\hline 2001 & 34.41 & 29.36 & 26.57 & 8.86 \\
\hline 1999 & 36.07 & 31.44 & 23.68 & 10.49 \\
\hline 1997 & 38.13 & 31.10 & 20.28 & 9.05 \\
\hline 1995 & 35.46 & 33.92 & 21.57 & \\
\hline
\end{tabular}

Table 5. Trend in hiring outside services (BRAZILIAN..., 2009).

\begin{tabular}{|c|c|c|c|}
\hline \multirow{2}{*}{ Year } & \multicolumn{3}{|c|}{ Trend in contracting out services $(\%)$} \\
\cline { 2 - 4 } & Enlarge & Retain & Decrease \\
\hline 2009 & 41.46 & 37.40 & 21.14 \\
\hline 2007 & 34.81 & 50.63 & 14.56 \\
\hline 2005 & 42.37 & 45.77 & 11.86 \\
\hline 2003 & 44.44 & 49.21 & 6.35 \\
\hline 2001 & 51.77 & 41.14 & 7.09 \\
\hline 1999 & 46.43 & 45.53 & 8.04 \\
\hline 1997 & 64.10 & 28.21 & 7.69 \\
\hline 1995 & 66.49 & 27.32 & 6.19 \\
\hline
\end{tabular}

Table 6. Deployment of resources in maintenance (BRAZILIAN..., 2009).

\begin{tabular}{|c|c|c|c|c|}
\hline \multirow{2}{*}{ Year } & \multicolumn{4}{|c|}{ Application of resources in maintenance (\%) } \\
\cline { 2 - 5 } & Corrective & Preventive & Predictive & Other \\
\hline 2009 & 29.85 & 38.73 & 13.74 & 17.68 \\
\hline 2007 & 25.61 & 38.78 & 16.09 & 18.51 \\
\hline 2005 & 32.11 & 39.03 & 17.76 & 12.38 \\
\hline 2003 & 29.98 & 35.49 & 18.87 & 17.41 \\
\hline 2001 & 28.05 & 35.67 & 17.17 & 19.14 \\
\hline 1999 & 27.85 & 35.84 & 18.54 & 27.18 \\
\hline 1997 & 25.53 & 28.75 & 18.64 & 13.56 \\
\hline 1995 & 32.80 & 35.00 & & \\
\hline
\end{tabular}

surpassed the traditional "leader" of these indicators - cost - by the very need for companies to meet their clients in specific deadlines.

In addition to these indicators, some pointed out in the specialist literature as being most important to evaluate the performance of maintenance; two other indicators are also fairly adopted in businesses surveyed by ABRAMAN. One is the analysis of the stock in relation to the total cost of maintenance and the second is the inventory turnover of maintenance. These data are presented in Table 8.

This indicator remained stable in the last two surveys. One sees a decrease in stock value, partly for the partnership that the companies are developing with their suppliers and the timing of deliveries of parts based on the dates of preventive maintenance.

\subsection{Operational readiness}

As shown by the survey, the indicator that companies are more aware today is the availability of your equipment. Data from the operational availability and unavailability to perform maintenance are presented in Table 9.

There was a perceived improvement in operational availability rate, reflecting greater attention to maintenance and the need to maintain the equipment available to most of the time because of the flexibility of demand and growing demand for compliance with deadlines, more short.

\subsection{Average age of equipment}

The average age of equipment used in the surveyed companies is presented in Table 10. To conduct the survey, five were specified age-bands, where one observes a 
Table 7. Indicators maintenance (BRAZILIAN..., 2009).

\begin{tabular}{|c|c|c|c|c|c|r|r|r|r|}
\hline \multicolumn{9}{c}{ Key performance indicators used (Degree of Importance - DI) } & DI 2009 \\
\hline Type & $\mathbf{1 9 9 5}$ & $\mathbf{1 9 9 7}$ & $\mathbf{1 9 9 9}$ & $\mathbf{2 0 0 1}$ & $\mathbf{2 0 0 3}$ & $\mathbf{2 0 0 5}$ & $\mathbf{2 0 0 7}$ & $\mathbf{2 0 0 9}$ & \\
\hline Costs & 26.21 & 26.49 & 26.32 & 25.91 & 21.45 & 21.96 & 20.33 & 18.98 & 2 \\
\hline Frequency of failure & 17.54 & 12.20 & 14.24 & 16.22 & 11.66 & 12.17 & 9.75 & 9.81 & 6 \\
\hline Customer Satisfaction & 13.91 & 11.01 & 11.76 & 11.86 & 8.62 & 8.11 & 8.93 & 9.38 & 7 \\
\hline Availability & 25.20 & 24.70 & 22.60 & 23.24 & 19.58 & 19.81 & 18.51 & 20.68 & 1 \\
\hline Rework & 9.07 & 5.65 & 8.36 & 8.96 & 6.06 & 6.68 & 3.97 & 5.33 & 8 \\
\hline Backlog & 8.07 & 6.55 & 8.98 & 10.41 & 9.32 & 6.92 & 11.57 & 10.02 & 5 \\
\hline Do not use & - & 2.09 & 2.79 & 1.22 & 1.63 & 0.72 & 0.33 & 1.07 & 9 \\
\hline MTBF & - & - & - & - & 11.89 & 11.69 & 14.21 & 12.79 & 3 \\
\hline MTTR & - & - & - & - & 9.56 & 11.46 & 11.74 & 11.94 & 4 \\
\hline Other indicators & - & 11.31 & 4.95 & 2.18 & 0.23 & 0.48 & 0.66 & 0.00 & 10 \\
\hline
\end{tabular}

Table 8. Indices related to inventories (BRAZILIAN..., 2009).

\begin{tabular}{|l|c|c|c|c|c|c|c|}
\hline \multicolumn{1}{|c|}{ Stock } \\
\hline \multicolumn{1}{|c|}{ Rates } & $\mathbf{1 9 9 7}$ & $\mathbf{1 9 9 9}$ & $\mathbf{2 0 0 1}$ & $\mathbf{2 0 0 3}$ & $\mathbf{2 0 0 5}$ & $\mathbf{2 0 0 7}$ & $\mathbf{2 0 0 9}$ \\
\hline Value of stock / Total cost of maintenance (\%) & 16.00 & 13.00 & 11.95 & 11.48 & 14.02 & 13.11 & 13.11 \\
\hline Turnover of inventory (months) & 5 & 4 & 4 & 4 & 4 & 5 & 5 \\
\hline
\end{tabular}

Table 9. Indicators of operational availability (BRAZILIAN..., 2009).

\begin{tabular}{|c|c|c|c|c|c|c|c|}
\hline \multicolumn{8}{|c|}{ Indicators of operational availability (\%) } \\
\hline Rates & 1997 & 1999 & 2001 & 2003 & 2005 & 2007 & 2009 \\
\hline Operational readiness & 85.82 & 89.30 & 91.36 & 89.48 & 88.20 & 90.82 & 90.27 \\
\hline Unavailability due to maintenance & 4.74 & 5.63 & 5.15 & 5.82 & 5.80 & 5.30 & 5.43 \\
\hline
\end{tabular}

Table 10. Average age of equipment (BRAZILIAN..., 2009).

\begin{tabular}{|c|c|c|c|c|c|c|}
\hline \multicolumn{6}{|c|}{ Average age of equipment (\%) } & \multirow{2}{*}{$\begin{array}{c}\text { Mean age in } \\
\text { years }\end{array}$} \\
\hline Year & 0 to 5 years & 6 to 10 years & 11 to 20 years & 21 to 40 years & Over 40 years & \\
\hline 2009 & 10.65 & 27.05 & 34.43 & 22.95 & 4.92 & 16.73 \\
\hline 2007 & 10.32 & 23.87 & 33.55 & 31.61 & 0.65 & 17.27 \\
\hline 2005 & 4.50 & 26.13 & 45.05 & 20.72 & 3.60 & 16.95 \\
\hline 2003 & 13.49 & 21.43 & 37.30 & 26.98 & 0.79 & 16.38 \\
\hline 2001 & 7.75 & 16.90 & 45.07 & 28.17 & 2.11 & 17.97 \\
\hline 1999 & 6.90 & 21.55 & 50.86 & 20.69 & 0.00 & 15.96 \\
\hline 1997 & 6.96 & 22.61 & 53.04 & 17.39 & 0.00 & 15.51 \\
\hline 1995 & 6.77 & 21.88 & 50.52 & 19.79 & 1.04 & 16.20 \\
\hline
\end{tabular}

concentration in the central lanes, between six and forty years. In extreme ranges, where the new and the older, there are is a reduction in the index, but there is an increase in new equipment, emphasizing the modernization of the machinery industry in Brazil.

For the data presented, we can see a small variation in the average age of equipment and plants, which can be measured by the increase in equipment over the age of 40 years, from $0.65 \%$ to $4.92 \%$.

\subsection{Training for maintenance personnel}

As companies seek continuous improvement of its processes, including maintenance, is one of the indicators analyzed the supply of skilled manpower. The index of hours of training in relation to hours available for maintenance is presented in Table 11.

The indicator was stable in the last three surveys. This index is very important because it measures the investment in skills, a factor that may be important for improving the quality of services and reducing turnover of maintenance personnel.

\section{Case study}

The company uses three indicators for the maintenance sector. The first assesses the number of scheduled preventive maintenance was performed. This indicator assesses the percentage held by dividing the number of maintenance services performed by the programmed number. Moreover, 
Table 11. Hours of training for maintenance (BRAZILIAN..., 2009).

\begin{tabular}{|c|c|}
\hline \multicolumn{2}{|c|}{ Training hours / hours available for maintenance (\%) } \\
\hline Year & \% \\
\hline 2009 & 3.10 \\
\hline 2007 & 3.43 \\
\hline 2005 & 3.35 \\
\hline 2003 & 2.89 \\
\hline 2001 & 3.30 \\
\hline 1999 & 2.94 \\
\hline 1997 & 3.50 \\
\hline 1995 & 3.04 \\
\hline
\end{tabular}

since the goal is the percentage, there may be some equipment that was scheduled and maintenance is not carried, making it ineffective in evaluating the effectiveness of maintenance planning by this method. The second indicator is a direct relationship between hours of corrective maintenance and preventive maintenance hours. This relationship identifies whether interventions are proceeding as planned and if the frequency used (based on time) is or is not the best parameter for planning. The third looks at the total amount of hours scheduled for production, comparing them to the hours used for preventive and corrective maintenance, identifying the nature of maintenance, whether electrical or mechanical.

For the current indicators, the indices presented at period analysis showed the following results. For the indicator of service maintenance plan, the twelve-month period evaluated, the company responded to $100 \%$ of planned maintenance in two months. The target for this indicator is to attend at least $90 \%$ of planning. In four months this target was not met and the other six superior service that goal. During this period, the cumulative rate is $90.23 \%$ attendance; presented in the first column of Figure 3.

Analyzing the percentage of preventive and corrective maintenance performed in comparison with the total amount of hours scheduled for production, it can be seen that as the roof of corrective maintenance is $1.3 \%$ of scheduled hours, the indicator was met in two months. This result is shown in Figure 4.

The total hours scheduled for production during the year studied was 32,038 hours and ten minutes. We performed 2503 hours and forty minutes of preventive maintenance, representing $7.81 \%$ of total scheduled hours. In corrective maintenance were 510 hours and 39 minutes, i.e. $1.59 \%$ of scheduled hours; value above the proposed target of $1.3 \%$. Of the total hours of corrective maintenance, 372 hours and six minutes were related to mechanical problems, $72.87 \%$ of cases. The remaining $27.13 \%$ or 138 hours and 33 minutes were stopped for corrective maintenance on electrical systems of equipment. In comparison with the indicators measured and disclosed by ABRAMAN, the company has studied

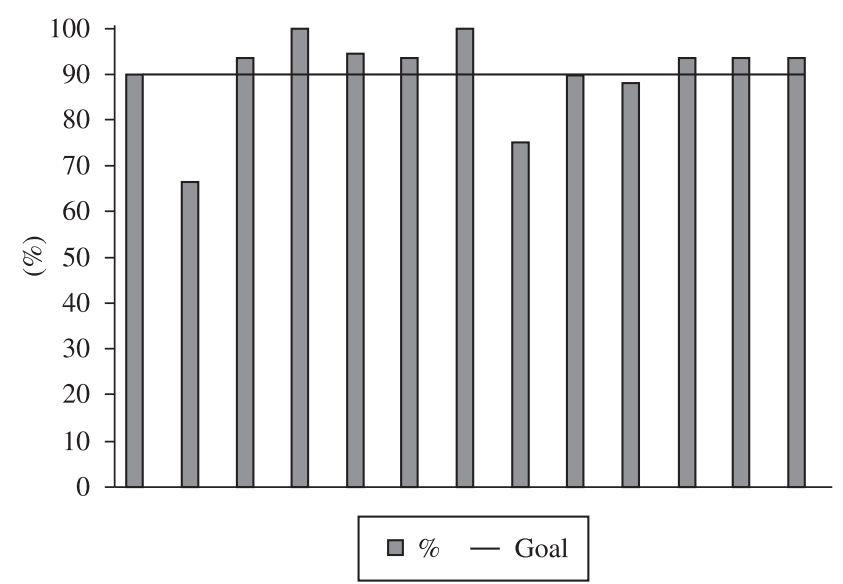

Figure 3. Percentage of care plan maintenance compared to the goal.

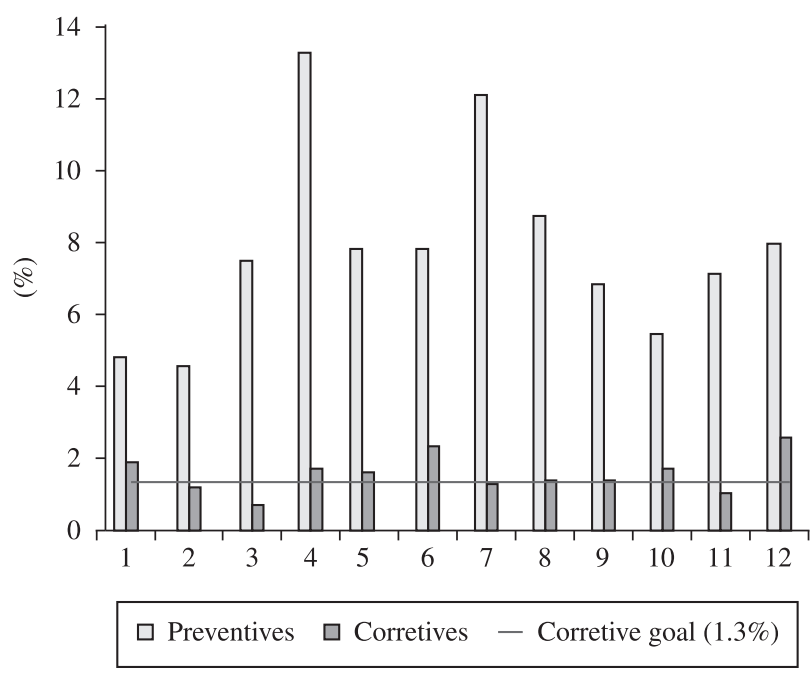

Figure 4. Percentage of preventive and corrective maintenance.

the following situation in relation to data maintenance personnel, maintenance type adopted and maintenance investment. The average age of equipment is 25 years old, and does not track the average time between failures and mean time to repair of maintenance.

The company studied has a total of 370 employees. Of this total, 56 people are involved in maintenance, 50 mechanics and electricians six, creating a percentage of $15.13 \%$ of the total. Comparing this value with the data released by ABRAMAN can see that there are a number of people connected with the maintenance than the average of the surveyed companies. To address the demands left as a result, there is the hiring of external services, but the trend is to professionalize and qualify internal staff to increase the cash of the company by number of people involved in maintenance. This may explain the fact that the goal of serving the number of planned maintenance was not 
achieved in a few months of the study period. It also explains the fact that the goal of time spent on corrective maintenance has been overcome. If you compare, though, the number of mechanics to electricians, it is the percentage of hours of corrective maintenance mechanic high, since there are eight times more mechanical electricians, confirming that there is need to improve the effectiveness of maintenance mechanics, is with training or with the hiring of personnel.

The maintenance staff turnover is $3.57 \%$. If after the division of mechanical and electrical sector in the turnover rate in the sector of electrical maintenance was $33.33 \%$, whereas the outputs that were in the maintenance sector were electricians. This rotation is similar to the national average. Can be examined, since the mechanical maintenance on company studied is highly technological since the small number of companies in the sector for action. The activity of industrial electricity, and the overall need for different types of companies, has generated a need for professionals in the region assessed in relation to growth and birth of firms in different sectors.

Considering only the realization of investment in maintenance s, the company has a rate of $1.69 \%$ on gross sales. If we compare with data researched by ABRAMAN is a low rate, but add to the value of the total manpower available for maintenance, this rate rises to $3.36 \%$ on revenues. Still, given the below average $4.14 \%$; this item identifying an improvement opportunity for the company.

The maintenance of the type adopted is prevention, which aims to keep equipment in operating condition and perform the intervention before problems arise. The biggest disadvantage of preventive maintenance is the cost, since replacing parts that could have a greater enjoyment of life. Even if the goals of achieving these are, on average, being answered, it is necessary to improve this indicator so that the operational availability is also enhanced. With the direct relationship between the availability and efficiency indicators, scrap and rework is notable that the improvement in the management of maintenance will help the company reduce its operating costs.

From the data collection was created an interdisciplinary group working to make improvements in the management system of maintaining the production line analyzed. To do so, followed the methodology presented in Figure 1. The first step was to define the objectives of the work and for what period of time expected to achieve the proposed results. Initially we set the goals to be achieved would be related to the production process, or equipment to provide conditions for working with the productivity and quality planning. For that we chose as a model for managing maintenance, TPM, for their involvement with any organization, not only with the specific area of maintenance.

With the management model chosen, we elaborated an action plan for carrying out tasks, and the first action was to enable all people involved. With that he got a better understanding and participation in the proposed activities. With data from production reports, which specify the equipment downtime and its causes were organized actions to improve focus. The points of greatest importance to the production process. Also created an integration between staff of the production process and maintenance sector, for which the information generated by the production were available and used when planning of preventive maintenance, prioritizing items where failure could occur more quickly. In parallel, actions were taken to improve maintenance, which were held together by teams of maintenance and production.

After the initial actions were made to prevent the recurrence of problems, measures against damage to equipment and forced the implementation of control and evaluation of maintenance. This occurred by monitoring the initial goals set forth by the audit group and the model for maintenance planning. With the system running, went to analysis and improvement of the life cycle of equipment, monitoring the frequency of interventions and the availability of equipment for production. The whole process needs to evolve; the current phase seeks continuous improvement and use of new techniques, such as the change in the layout of the production line studied and the proposed extension of this model of maintenance management for all production lines company.

\section{Conclusions}

Considering the indicators originally presented by the company, it is observed that they are not sufficient to evaluate the performance of maintenance. The indicator of the percentage of care provided to the plan, although during the study period show that the cumulative rate of $90.23 \%$ is not shown if the maintenance were performed on the planned equipment. This fact may cause the non-fulfillment of the goal of corrective maintenance, $1.3 \%$ for ten of the twelve months evaluated. Moreover, the percentage of unavailability due to maintenance, $9.41 \%$ are added to corrective and preventive maintenance is much higher than the average rate submitted by the research of ABRAMAN for the last year published, $5.43 \%$.

Thus, from this study was controlled the frequency of failure of each device, identifying the highest incidence of breaks from the data generated by the maintenance work orders. These data generate Pareto charts for easier viewing of the equipment with the highest losses. For the future, this same control is performed by equipment, controlling the set that has more breakdowns and maintenance.

From Figure 2, one can see that the company has studied targets for planned maintenance; productive performance goals in order to evaluate the efficiency of each production line and the overall efficiency of the plant and product quality goals and processes as well defined. In addition to control some variables that influence them, but without a 
performance evaluation of goals. Therefore, it is suggested that adopt specific goals: number and duration of preventive maintenance, equipment availability, number of unplanned maintenance, rework maintenance; internal customer satisfaction, where the manufacturing sector. By adopting these goals will become easier to identify the causes of maintenance problems, as well as decision making and action to increase compliance with the plan of maintenance, increased availability of equipment for production and reduction in number of corrective maintenance.

Still, beyond the adoption of new indicators for maintenance, it is also suggested the use of technical method in all production lines of business, to assist the development of maintenance plan, in addition to experience and report data. Suggestions for how this method can be used: Networks PERT / CPM, or critical path method, the reliability-based maintenance, FMEA - Analysis of Failure Mode and Effect, Total Productive Maintenance and Six Sigma.

This study brought new indicators as a contribution to the assessment of maintenance performance for the company studied, and the introduction of a sequence for planning preventive maintenance of equipment, presenting a methodology of work, being that this could be adopted in other lines company's production and other factories of the group studied. Also showed that the studied company can invest more money in maintenance activity, particularly in the training of people already working in industry and in hiring staff. It is estimated that an investment of $\mathrm{R} \$ 46,800$ per month in maintenance, to equate value to the average of the research presented by ABRAMAN (BRAZILIAN..., 2009), may increase the efficiency of the production area by about three percentage points, representing a reduction in production time for the level of current sales of two days, or increase the amount produced by $4.2 \%$ per month. With these values, the return on investment would be very attractive for the company, considering a reference rate of $20 \%$.

\section{References}

BRAZILIAN ASSOCIATION OF MAINTENANCE ABRAMAN. The state of maintenance in Brazil: 2009 national document. Rio de Janeiro: ABRAMAN, 2009.

AHRÉN, T.; PARIDA, A. Maintenance performance indicators (MPIs) for benchmarking the railway infrastructure: a case study. Benchmarking: An International Journal, v. 16, n. 2, p. 247-258, 2009.

ANVARI, F.; EDWARDS, R.; STARR, A. Evaluation of Overall Equipment Effectiveness based on market. Journal of Quality in Maintenance Engineering, v. 16, n. 3, p. 256-270, 2010. http://dx.doi.org/10.1108/13552511011072907

BRANCO FILHO, G. Dictionary of Maintenance, Reliability and Quality. Rio de Janeiro: Modern Science, 2006.
KHALIL, J.; SAAD, S. M.; GINDY, N. An integrated cost optimization model for industrial maintenance equipment. Journal of Quality in Maintenance Engineering, v. 15, n. 1, p. 106-118, 2009. http://dx.doi. org/10.1108/13552510910943912

KHAN, M. R. R.; DARRAB, I.A. Development of analytical relation between maintenance, quality and productivity. Journal of Quality in Maintenance Engineering, v. 16, n. 4, p. 341-353, 2010. http://dx.doi. org/10.1108/13552511011084508

MÁRQUEZ, A. C. et al. The maintenance management framework: a Practical View to maintenance management. Journal of Quality in Maintenance Engineering, v. 15, n. 2, p. 167-178, 2009. http://dx.doi. org/10.1108/13552510910961110

MOAYED, F.; SHELL, R. L. Comparison and evaluation of maintenance operations or in lean versus non-lean production systems. Journal of Quality in Maintenance Engineering, v. 15, n. 3, p. 285-296, 2009. http://dx.doi. org/10.1108/13552510910983224

MORAES, E. A. P.; MARIANO, S. R. H. A rereading of the main models of governance of information technology. Vianna Sapiens, v. 1, n. 1, p. 201-217, 2010.

MUCHIRI, P. et al. Development of maintenance function, performance indicators and measurement frame work. International Journal of Production Economics, v. 131 , n. 1 , p. $295-302$, 2011. http://dx.doi.org/10.1016/j. ijpe.2010.04.039

OTANI, M.; MACHADO, W. V. The proposed development of industrial maintenance management in the pursuit of excellence and world class. Industrial Management magazine, v. 4, n. 2, p. 1-16, 2008.

PARIDA, A. Study and analysis of maintenance performance indicators (MPIs) for LKAB: a case study. Journal of Quality in Maintenance Engineering, v. 13, n. 4, p. 325-337, 2007. http://dx.doi.org/10.1108/13552510710829434

PARIDA, A.; KUMAR, U. Maintenance performance measurement(MPM): issues and challenges. Journal of Quality in Maintenance Engineering, v. 12, n. 3, p. 239-251, 2006. http://dx.doi.org/10.1108/13552510610685084

REIS,A.B.C.; COSTA,A.P.C. S.;ALMEIDA, A. T. Planning and competitiveness in maintenance management: an exploratory study in manufacturing companies. Journal of Quality in Maintenance Engineering, v. 15, n. 3, p. 259-270, 2009. http://dx.doi.org/10.1108/13552510910983206

SELLITTO, M. A.; WALTER, C. Performance evaluation of a manufacturing electronic equipment in terms of competition. Revelation Productions, v. 16, n. 1, p. 34-47, 2006.

SILVA, C. M. I.; CABRITA, C. M. P.; MATIAS, J. C. O. Proactive reliability maintenance: a case study regarding maintenance service costs. Journal of Quality in Maintenance Engineering, v. 14, n. 4, p. 343-355, 2008. http://dx.doi. org/10.1108/13552510810909957 